\title{
Anemia Requiring Transfusion in Breast Cancer Patients on Dose- dense Chemotherapy: Prevalence, Risk Factors, Cost and Effect on Disease Outcome.
}

\author{
Parth Sharma \\ Christian Medical College and Hospital: Christian Medical College Vellore https://orcid.org/0000-0003-4954-6031 \\ Josh Thomas Georgy \\ Christian Medical College and Hospital: Christian Medical College Vellore \\ Anand George Andrews \\ Christian Medical College and Hospital: Christian Medical College Vellore \\ Ajoy Oommen John \\ Christian Medical College and Hospital: Christian Medical College Vellore \\ Anjana Joel \\ Christian Medical College and Hospital: Christian Medical College Vellore \\ Raju Titus Chacko \\ Christian Medical College and Hospital: Christian Medical College Vellore \\ Ashish Singh ( $\square$ todrashish@gmail.com) \\ Christian Medical College and Hospital: Christian Medical College Vellore https://orcid.org/0000-0002-0981-4751
}

\section{Research Article}

Keywords: Anemia, dose-dense chemotherapy, breast cancer

Posted Date: November 15th, 2021

DOI: https://doi.org/10.21203/rs.3.rs-990324/v1

License: (c) (i) This work is licensed under a Creative Commons Attribution 4.0 International License. Read Full License

Version of Record: A version of this preprint was published at Supportive Care in Cancer on March 21st, 2022. See the published version at https://doi.org/10.1007/s00520-022-06970-2. 


\section{Abstract}

Purpose: Dose dense chemotherapy improves survival but also increases toxicity and treatment related cost. Here we report the prevalence of anemia, understand the risk factors of chemotherapy related anemia and determine the cost and time-delay associated with transfusion requirement in Indian non-metastatic breast cancer patients on dose dense preoperative chemotherapy.

Methods: In this study, 116 triple negative breast cancer (TNBC) patients were treated preoperatively with Docetaxel and Cyclophosphamide alternating with Epirubicin and Cisplatin every 2-weekly. Patients were evaluated for anemia pre-and post-chemotherapy. We examined trends in the cell counts, transfusion requirement, time to transfusion as well as risk factors associated with transfusion during treatment, along with delay in treatment due to anemia and the additional cost incurred.

Results: One hundred and sixteen women with high-risk non-metastatic TNBC were treated. Median age was 44.5 years. $56.1 \%$ had stage III disease. Delivery of $6 / 8$ planned doses was achieved in $98.3 \%$ of patients, and all 8 doses in $86 \%$ patients. Anemia was detected at baseline in $54(46.5 \%)$ patients with mild $(10-12 \mathrm{~g} / \mathrm{dl})$ anemia in $42(36.2 \%)$ patients and moderate $(8-10 \mathrm{~g} / \mathrm{dl})$ in $12(10.3 \%)$ patients. Forty-four patients (37.9\%) required transfusion during chemotherapy with 55(47.4\%) patients having grade $1-2$ anemia and $40(34.5 \%)$ patients having grade 3 anemia. The factors associated with transfusion were low grade of tumor (OR 2.48 (95\% Cl 1.08 - 5.68), p = 0.025), hemoglobin post 2 cycles of chemotherapy (OR 1.74 (95\% Cl 1.21- 2.51), $p=0.003)$, thrombocytopenia grade 3 or 4 (OR $4.35(95 \% \mathrm{Cl} 1.062-17.827), p=0.034)$ and drop in hemoglobin after 2 cycles (OR $1.65(95 \% \mathrm{Cl} 1.09-2.48), \mathrm{p}=0.017)$. Nearly one fourth of the study population had a delay between two cycles of chemotherapy due to anemia. A median additional cost of Rs 7000 (IQR-Rs 7000 - Rs 14000) was incurred on transfusion.

Conclusion: Anemia is a common toxicity associated with dose dense chemotherapy during curative breast cancer treatment leading to delay in treatment and increased cost. Low grade tumor, grade 3 or 4 thrombocytopenia and Grade 2 or higher anemia after 2 cycles of chemotherapy are risk factors for blood transfusions during treatment.

\section{Introduction}

Anemia is the commonest complication encountered while treating cancer patients. It is present in $50-65 \%$ of cancer patients at the time of diagnosis [1-5] and rises to as high as $90 \%$ after completion of treatment.[6] Anemia has shown to not only affect quality of life in cancer patients but also is associated with reduced treatment effectiveness, increased mortality and increased transfusion requirement $[5,7-9]$.

Anemia in cancer patients is multifactorial and can be due to nutritional deficiencies, hemolysis, bleeding, anemia of chronic disease or due to the myelosuppressive chemotherapeutic agents.

Identifying factors which can predict development of anemia during the course of treatment will help in improving supportive care and individual management of patients at risk of developing severe anemia. [10] Baseline hemoglobin, body mass index (BMI), high haptoglobin, high ferritin and glomerular filtration rate (GFR) are considered important predictors for developing anemia. [6, 10-14]

In this study we looked at tumor characteristics and blood parameters (done prior to each cycle of chemotherapy) and the change in these parameters with each cycle of chemotherapy. We aimed to identify the cost of treating anemia, delay in cancer treatment and its impact on the outcome of disease.

\section{Method}

\section{Study design and patients}

This retrospective cohort study was done at a tertiary care referral teaching hospital in South India. We recruited 116 patients from January 2017 to January 2020, with triple negative breast cancer. All patients were treated with a regimen of dose dense chemotherapy. Patients were planned for a total of 8 cycles of chemotherapy every 2 weeks. Four cycles of Docetaxel $(75 \mathrm{mg} / \mathrm{m} 2)$ and Cyclophosphamide $(600 \mathrm{mg} / \mathrm{m} 2) \mathrm{were}$ given alternating with four cycles of Epirubicin $(90 \mathrm{mg} / \mathrm{m} 2)$ and Cisplatin $(60 \mathrm{mg} / \mathrm{m} 2)$. The details of the clinical efficacy of this chemotherapy regimen have been reported previously [14].

Patients were transfused if their hemoglobin level dropped below $8 \mathrm{~g} / \mathrm{dL}$ or in case of heart failure due to anemia. Cost of transfusions and delay in treatment due to transfusion was also evaluated.

The study was approved by the Institutional Review Board and Ethics committee, Christian Medical College Vellore, Tamil Nadu, India (IRB number: 13960 [Retro] dated 28.04.21) 


\section{Data Collection}

We collected baseline demographic details such as age, gender and place of origin along with tumor related characteristics such as tumor histology, tumor grade, TNM stage. Treatment details such as number of cycles given and the toxicity during chemotherapy was also documented. We measured the MCV, MCH, MCHC, RDW and Hemoglobin at baseline, in between chemotherapy cycles, and at the end of treatment. Anemia, neutropenia and thrombocytopenia were defined based on the WHO definition and graded based on CTCAE v5.0. Data was collected regarding the need of transfusion, time of transfusion and number of packed cells transfused. Dose delay was defined as a delay of $>2$ days from the expected administration of a given cycle. Menopausal status was defined as amenorrhea for the last 12 months.

\section{Statistical analysis}

Continuous variables were summarized using the descriptive statistics. We used mean and standard deviation (SD) for variables with a gaussian distribution and median and inter quartile range (IQR) for variables with a skewed distribution. Univariate analyses were carried out using the chi-square test. Quantitative and qualitative variables were transformed, whenever possible, into ordinal variables, using predefined cutoff points. The results of univariate analyses are presented with adjusted odds-ratio, $95 \%$ confidence intervals ( $95 \% \mathrm{Cl}$ ) and $\mathrm{p}$-value. Significance levels were defined at 0.05. All analyses were performed using IBM SPSS Statistics 25 software and RStudio (Version1.4.1717).

\section{Results}

\section{Baseline characteristics and Prevalence of anemia}

The mean age of the population was $43.3 \pm 8.7$ years. Stage II disease was seen in $41.1 \%$ of patients and $56.1 \%$ had stage III disease. Delivery of $6 / 8$ planned doses was achieved in $98.3 \%$ of patients, and all 8 doses in $86 \%$.

Nearly half (47.4\%) of all patients were anemic at the time of diagnosis with 44(37.9\%) patients having CTCAE v5.0 Grade 1 anemia, $10(8.6 \%)$ patients having Grade 2 anemia and 1(0.9\%) patient having Grade 3 anemia. All of these patients developed anemia during the course of chemotherapy. Table II shows the hematological toxicities related to the chemotherapy. Only 1 out of 116 patients was evaluated for cause of anemia and only $24(20.6 \%)$ patients received any form of iron supplementation.

\section{Transfusions}

A total of $44(37.9 \%)$ patients required at least 1 unit of blood transfusion during chemotherapy. A total of 73 units of packed red cells were transfused in the study population with a maximum of 4 units being transfused per patient. There was a mean rise of $1.7 \pm 0.5 \mathrm{~g} / \mathrm{dl}$ in hemoglobin level following transfusion.

\section{Risk factors}

Patients in the transfusion group had comparable mean age, disease status and hematological characteristics as compared with the patients who did not require transfusion. Differences were noticed in both the groups with respect to number of cycles received, menopausal status and grade of tumor (Table I).

A greater percentage (54.5\% vs $43 \%$ ) of patients were anemic at the time of diagnosis in the transfusion group, however this difference was not statistically significant. Univariate analysis (Table III) shows that drop in hemoglobin after 2 cycles of chemotherapy (OR 1.649(1.0942.485), $\mathrm{p}=0.017$ ), hemoglobin post 2 cycles of chemotherapy (OR 1.74 ( $95 \% \mathrm{Cl} 1.21-2.51), \mathrm{p}=0.003$ ), high grade thrombocytopenia (OR 4.351(1.062-17.827), $p=0.034$ ) and low grade of tumor (OR 2.48 (95\% Cl 1.08 - 5.68), $p=0.025$ ) were risk factors for developing anemia requiring transfusion. Graph A (Time to event analysis) shows patients with low grade tumors were more likely to be transfused. No other baseline factor was significantly associated with transfusion requirement.

\section{Impact of anemia}

Impact of anemia was assessed in terms of delay in treatment and cost associated with transfusion. Time to event analysis (Graph B) showed that patients who received 7 or less chemotherapy cycles were more likely to be transfused. This could be explained by the early termination of chemotherapy in patients who developed severe anemia requiring transfusion. A total of 27 patients (23.2\%) had a delay between two cycles of chemotherapy due to anemia. Delay ranged from a minimum of 2 days to a maximum of 16 days with median delay of 6.5 (4.2 - 8.5) days. Treating triple negative breast cancer with the above-mentioned regimen costs approximately Rs 170,000 for 8 cycles (including drugs, hospital charges and investigations) if there are no adverse events. A median cost of Rs 7000 (Rs 7000 - Rs 14000 ) was spent additionally on transfusion. 
Transfusion requirement, delay in chemotherapy, baseline anemia and pre-op hemoglobin did not have an impact on the outcome of the disease, assessed in terms of pathological complete response (TO/Tis NO). Data on the complete response rates and disease-free survival have been published separately [15].

\section{Discussion}

This paper describes the prevalence of anemia and transfusion practices in the routine treatment of early TNBC. Dose dense chemotherapy has been shown to improve clinical outcomes in breast cancer patients [16] but is associated with a higher incidence of anemia [17]. The incidence of anemia was found to be $47.4 \%$, similar to other studies conducted in breast cancer patients. [1-5] Transfusion requirement in our population was higher than expected. At least 1 unit of Packed cells was transfused in $37.9 \%$ of the patients as compared to other studies conducted in breast cancer patients - $28.1 \%$ as seen in Moebus et al [17] and $11.4 \%$ as seen in Jones et al. [18] This could be due to the added toxicity of Cisplatin based regimen used in our study population. [19] A greater percentage of patients who were transfused were found to be anemic at the time of diagnosis. Baseline anemia and baseline hemoglobin have been identified to be independent risk factors for transfusion in multiple studies. [10-13] However, in our study the association was not found to be statistically significant.

Hemoglobin after cycle 2 was found to be a statistically significant risk factor associated with transfusion. As depicted in the Graph C, the patients who got transfused had a steady drop in hemoglobin as compared to the patients who did not get transfused. This can help us in identifying patients who might require transfusion based on the trend in their hemoglobin values at an early stage of treatment with chemotherapy.

Patients with grade 3 or 4 thrombocytopenia were more likely to be transfused. This could be explained by a greater extent of bone marrow suppression in patients requiring transfusion. We noticed that patients with low grade tumor were more likely to get transfused. We hypothesize that the slow growing nature of low-grade tumors could be responsible for anemia of chronic disease, thus requiring transfusion.

The burden of chemotherapy related anemia was assessed in terms of added cost of transfusion and delay in treatment. Time burden associated with out-patient transfusion in cancer patients has been studied previously. [20] We found that nearly one fourth of our patients had a delay of at least 2 days in their chemotherapy schedule. The direct cost of transfusion and the indirect cost due to delay in treatment lead to increase in the overall cost of treatment of breast cancer.

The main limitations of our study included the small number of patients and small number of events per variable. As another limitation, the study included only triple negative breast cancer patients. As the patients were given a Platinum based regimen, the transfusion requirement and degree of anemia might be exaggerated as compared to other pathological types of breast cancer for which usually non-platinum-based regimens are used. Baseline pretreatment evaluation of anemia was not uniform and therefore the underlying cause of anemia was not available for all our study population.

\section{Conclusion}

Anemia requiring transfusion is a common toxicity of dose dense chemotherapy. Patients experience substantial time burden due to delay along with additional cost of treatment of anemia due to chemotherapy. Early onset decline of hemoglobin within 2 cycles and low grade tumor were associated with subsequent transfusion requirement.

\section{Declarations}

Funding: Not applicable.

Conflicts of interest/Competing interests: The authors declare that there is no conflict of interests.

Availability of data and material: Patient data is being stored in a password protected computer which will can only be accessed by the first author and the corresponding author.

Code availability. Not applicable.

Authors' contributions: The authors had the following contributions: 


\begin{tabular}{|c|c|c|c|c|c|c|c|c|c|}
\hline \multirow{4}{*}{$\begin{array}{l}\text { Author(s) } \\
\text { Name }\end{array}$} & \multicolumn{9}{|c|}{ Responsibilities } \\
\hline & Research & Data & Laboratory & Interpretation & Preparation & Review of & Guide & Administration & Technical \\
\hline & and & collection & analysis & and & of & Manuscript & and & & Support \\
\hline & design & $\begin{array}{l}\& \\
\text { Analysis }\end{array}$ & & conclusion & Manuscript & & revision & & \\
\hline $\begin{array}{l}\text { Parth } \\
\text { Sharma }\end{array}$ & $\checkmark$ & $\checkmark$ & $\checkmark$ & $\checkmark$ & $\checkmark$ & $\checkmark$ & & & \\
\hline $\begin{array}{l}\text { Josh T. } \\
\text { Georgy }\end{array}$ & $\checkmark$ & $\checkmark$ & $\checkmark$ & $\checkmark$ & $\checkmark$ & $\checkmark$ & & & $\checkmark$ \\
\hline $\begin{array}{l}\text { Anand G. } \\
\text { Andrews }\end{array}$ & $\checkmark$ & $\checkmark$ & $\checkmark$ & $\checkmark$ & $\checkmark$ & $\checkmark$ & & & \\
\hline $\begin{array}{l}\text { Ajoy } 0 . \\
\text { John }\end{array}$ & $\checkmark$ & & & $\checkmark$ & $\checkmark$ & $\checkmark$ & & & $\checkmark$ \\
\hline $\begin{array}{l}\text { Anjana } \\
\text { Joel }\end{array}$ & $\checkmark$ & & & $\checkmark$ & & $\checkmark$ & & & $\checkmark$ \\
\hline $\begin{array}{l}\text { Raju T. } \\
\text { Chacko }\end{array}$ & $\checkmark$ & & & $\checkmark$ & & $\checkmark$ & & & $\checkmark$ \\
\hline $\begin{array}{l}\text { Ashish } \\
\text { Singh }\end{array}$ & $\checkmark$ & $\checkmark$ & & $\checkmark$ & $\checkmark$ & $\checkmark$ & $\checkmark$ & $\checkmark$ & $\checkmark$ \\
\hline
\end{tabular}

Ethics approval: The study was approved by the Institutional Review Board and Ethics committee, Christian Medical College Vellore, Tamil Nadu, India (IRB number: 13960 [Retro] dated 28.04.21)

Consent to participate: The patients consented for treatment and collection of data prior to initiation of treatment.

Consent for publication: As this was a retrospective study consent for publication was waived by the Institutional Ethics Committee.

\section{References}

1. John GK, Sanamandra S, Shet AS. Cancer Related Anemia in the Developing World: Risk Factors and Treatment Patterns. Blood. 2011;118(21):4747. doi:10.1182/blood.V118.21.4747.4747

2. Hospital S, Ababa A, Kifle E, Hussein M, Alemu J, Tigeneh W. Prevalence of Anemia and Associated Factors among Newly Diagnosed Patients with Solid Malignancy at Tikur Anbessa. 2019;2019.

3. Macciò A, Madeddu C, Gramignano G, et al. The role of inflammation, Iron, And nutritional status in cancer-related anemia: Results of a large, Prospective, Observational study. Haematologica. 2015;100(1):124-132. doi:10.3324/haematol.2014.112813

4. Ludwig H, Van Belle S, Barrett-Lee P, et al. The European Cancer Anaemia Survey (ECAS): A large, multinational, prospective survey defining the prevalence, incidence, and treatment of anaemia in cancer patients. Eur J Cancer. 2004;40(15):2293-2306. doi:10.1016/j.ejca.2004.06.019

5. Kanuri G, Sawhney R, Varghese J, Britto M, Shet A. Iron Deficiency Anemia Coexists with Cancer Related Anemia and Adversely Impacts Quality of Life. Published online 2016:1-11. doi:10.1371/journal.pone.0163817

6. Tas F, Eralp Y, Basaran M, et al. Anemia in oncology practice: relation to diseases and their therapies. Am J Clin Oncol. 2002;25(4):371379. doi:10.1097/00000421-200208000-00011

7. Knight K, Wade S, Balducci L. Prevalence and outcomes of anemia in cancer: A systematic review of the literature. Am J Med. 2004;116(7 SUPPL. 1):11-26. doi:10.1016/j.amjmed.2003.12.008

8. Glaspy J. Anemia and Fatigue in Cancer Patients. Published online 2001:1719-1724.

9. Demetri GD. Anaemia and its functional consequences in cancer patients: Current challenges in management and prospects for improving therapy. Br J Cancer. 2001;84(SUPPL. 1):31-37. doi:10.1054/bjoc.2001.1750

10. Chaumard N, Limat S, Villanueva C, et al. Incidence and risk factors of anemia in patients with early breast cancer treated by adjuvant chemotherapy. Breast. 2012;21(4):464-467. doi:10.1016/j.breast.2011.10.009 
11. Razzaghdoust A, Mofid B, Peyghambarlou P. Predictors of chemotherapy-induced severe anemia in cancer patients receiving chemotherapy. Support Care Cancer. 2020;28(1):155-161. doi:10.1007/s00520-019-04780-7

12. Barrett-Lee PJ, Ludwig H, Birgegård G, et al. Independent Risk Factors for Anemia in Cancer Patients Receiving Chemotherapy: Results from the European Cancer Anaemia Survey. Oncology. 2006;70(1):34-48. doi:10.1159/000091675

13. Vincent M, Dranitsaris G, Verma S, et al. The development and validation of a prediction tool for chemotherapy-induced anemia in patients with advanced nonsmall cell lung cancer receiving palliative chemotherapy. Support Care Cancer. 2007;15(3):265-272. doi:10.1007/s00520-006-0154-2

14. Family L, Xu L, Xu H, et al. The effect of chemotherapy-induced anemia on dose reduction and dose delay. Support Care Cancer. 2016;24(10):4263-4271. doi:10.1007/s00520-016-3258-3

15. Georgy JT, Singh A, Oommen A, et al. 261P A novel dose-dense alternating regimen of Docetaxel-Cyclophosphamide with EpirubicinCisplatin (ddDCEP) as neoadjuvant chemotherapy (NACT) for high-risk triple-negative breast cancer. Ann Oncol. 2020;31:S343. doi:10.1016/j.annonc.2020.08.070

16. Citron ML, Berry DA, Cirrincione C, et al. Randomized trial of dose-dense versus conventionally scheduled and sequential versus concurrent combination chemotherapy as postoperative adjuvant treatment of node-positive primary breast cancer: first report of Intergroup Trial C9741/Cancer and Leukemi. J Clin Oncol Off J Am Soc Clin Oncol. 2003;21(8):1431-1439. doi:10.1200/JC0.2003.09.081

17. Moebus V, Jackisch C, Schneeweiss A, et al. Adding epoetin alfa to intense dose-dense adjuvant chemotherapy for breast cancer: Randomized clinical trial. J Natl Cancer Inst. 2013;105(14):1018-1026. doi:10.1093/jnci/djt145

18. Leyland-Jones B, Bondarenko I, Nemsadze G, et al. A randomized, open-label, multicenter, phase III study of epoetin alfa versus best standard of care in anemic patients with metastatic breast cancer receiving standard chemotherapy. J Clin Oncol. 2016;34(11):11971207. doi:10.1200/JC0.2015.63.5649

19. Poggio F, Bruzzone M, Ceppi M, et al. Platinum-based neoadjuvant chemotherapy in triple-negative breast cancer: a systematic review and meta-analysis. Ann Oncol Off J Eur Soc Med Oncol. 2018;29(7):1497-1508. doi:10.1093/annonc/mdy127

20. Shreay S, Desrosiers MP, Corey-Lisle P, Payne K. A retrospective study to evaluate the time burden associated with outpatient red blood transfusions indicated for anemia due to concomitantly administered chemotherapy in cancer patients. Support Care Cancer.

2013;21(5):1335-1340. doi:10.1007/s00520-012-1671-9

\section{Tables}

Table I: Baseline characteristics 


\begin{tabular}{|c|c|c|}
\hline Characteristic & Not transfused $(n=72)$ & Transfused $(n=44)$ \\
\hline Age (years)* & $42.2 \pm 8.2$ & $45.1 \pm 9.3$ \\
\hline \multicolumn{3}{|l|}{ Stage $(n=107)$} \\
\hline Early Stage (I and II) & $28(26.0 \%)$ & $19(17.9 \%)$ \\
\hline Locally advanced (Stage III) & $36(33.6 \%)$ & $24(22.5 \%)$ \\
\hline \multicolumn{3}{|l|}{ Grade of tumor $(n=112)$} \\
\hline Low Grade (Grade I and II) & $16(13.7 \%)$ & $19(16.3 \%)$ \\
\hline High Grade (Grade III) & $53(45.6 \%)$ & $24(20.6 \%)$ \\
\hline \multicolumn{3}{|l|}{ Cycles completed ( $n=114)$} \\
\hline 7 or less & $7(10 \%)$ & $9(20.5 \%)$ \\
\hline Completed all 8 cycles & $63(90 \%)$ & $35(79.5 \%)$ \\
\hline Baseline Hemoglobin (mg/dl)* & $11.8 \pm 1.3$ & $11.6 \pm 1.1$ \\
\hline Baseline MCV (fL)* & $83.6 \pm 7.5$ & $84.6 \pm 7.8$ \\
\hline Baseline $\mathrm{MCH}(\mathrm{pg})^{*}$ & $27.0 \pm 3.1$ & $27.3 \pm 3.1$ \\
\hline Baseline MCHC $(\mathrm{g} / \mathrm{dL})^{*}$ & $32.2 \pm 1.3$ & $32.2 \pm 1.3$ \\
\hline Baseline RDW * & $15.1 \pm 3.8$ & $14.4 \pm 1.8$ \\
\hline \multicolumn{3}{|l|}{ Menopausal status } \\
\hline Premenopausal & $52(72.2 \%)$ & $25(56.8 \%)$ \\
\hline Post-menopausal & $20(27.3 \%)$ & $19(43.2 \%)$ \\
\hline \multicolumn{3}{|l|}{ ECOG score } \\
\hline 0 score & $50(69.4 \%)$ & $32(72.7 \%)$ \\
\hline 1-2 score & $22(30.6 \%)$ & $12(27.3 \%)$ \\
\hline \multicolumn{3}{|l|}{ Anemia at diagnosis } \\
\hline Grade I (10 - $12 \mathrm{~g} / \mathrm{dl})$ & $24(33.3 \%)$ & $20(45.4 \%)$ \\
\hline Grade II $(8-9.9 \mathrm{~g} / \mathrm{dl})$ and Grade III $(6.5-7.9 \mathrm{~g} / \mathrm{dl})$ & $7(9.6 \%)$ & $4(9.1 \%)$ \\
\hline
\end{tabular}

* Mean and standard deviation

Table Il: Hematological Toxicity of chemotherapy 


\begin{tabular}{|lll|}
\hline Characteristic & Not transfused $(\mathbf{n}=\mathbf{7 2})$ & Transfused $(\mathbf{n}=\mathbf{4 4})$ \\
\hline Anemia* $(\mathbf{n}=113) * *$ & & \\
\hline Grade I & $27(37.5 \%)$ & $4(9.1 \%)$ \\
\hline Grade II & $40(55.6 \%)$ & $27(61.4 \%)$ \\
\hline Grade III & & $13(29.5 \%)$ \\
\hline Drop in hemoglobin after 2 cycles $^{\star * *}(\mathbf{m g} / \mathbf{d l})$ & $1.25(0.42-1.97)$ & $1.75(1.00-2.40)$ \\
\hline Thrombocytopenia* & & \\
\hline Low Grade (Grade I and II) & $40(55.5 \%)$ & $24(54.5 \%)$ \\
\hline High Grade (Grade III and IV) & $3(4.2 \%)$ & $7(15.9 \%)$ \\
\hline Neutropenia* & & $9(20.4 \%)$ \\
\hline Low grade(Grade I and II) & $13(18.0 \%)$ & $11(25.0 \%)$ \\
\hline High grade(Grade III and IV) & $8(11.1 \%)$ & \\
\hline
\end{tabular}

*CTCAE v5.0 grading

** 2 patients were not anemic at the end of chemotherapy. Data missing for 3 patients in the Not transfused group.

$\star * \star$ Median and IQR

Table III: Univariate analysis

\begin{tabular}{|lll|}
\hline Characteristic & Odds ratio (95\% Cl) & Unadjusted p-Value \\
\hline Age & $1.04(0.99-1.09)$ & 0.09 \\
\hline Drop in Hemoglobin after 2 cycles & $1.65(1.09-2.48)$ & 0.017 \\
\hline Baseline Hemoglobin & $0.89(0.67-1.21)$ & 0.474 \\
\hline Baseline MCV & $1.02(0.99-1.07)$ & 0.533 \\
\hline Baseline MCH & $1.02(0.91-1.16)$ & 0.691 \\
\hline Baseline MCHC & $0.98(0.74-1.29)$ & 0.868 \\
\hline Baseline RDW & $0.90(0.76-1.07)$ & 0.235 \\
\hline Hemoglobin post cycle 2 & $1.74(1.21-2.51)$ & 0.003 \\
\hline Stage ( $\mathbf{n}$ 107) (Locally advanced vs. Early stage) & $0.98(0.45-2.14)$ & 0.561 \\
\hline Grade of tumor ( $\mathbf{n} \mathbf{1 1 2}$ ) (Low grade vs. High Grade) & $2.48(1.08-5.68)$ & $\mathbf{0 . 0 2 5}$ \\
\hline Cycles completed ( $\mathbf{n}=114)$ (8 cycles vs. 7 or less) & $0.43(0.15-1.26)$ & 0.100 \\
\hline Menopausal status (Postmenopausal vs. premenopausal) & $1.98(0.89-4.35)$ & 0.067 \\
\hline ECOG PS (1-2 vs. 0) & $0.85(0.37-1.96)$ & 0.437 \\
\hline Neutropenia Grade 3/4 & $2.67(0.98-7.27)$ & 0.070 \\
\hline Thrombocytopenia Grade 3/4 & $4.35(1.06-17.83)$ & $\mathbf{0 . 0 3 4}$ \\
\hline
\end{tabular}

Figures 

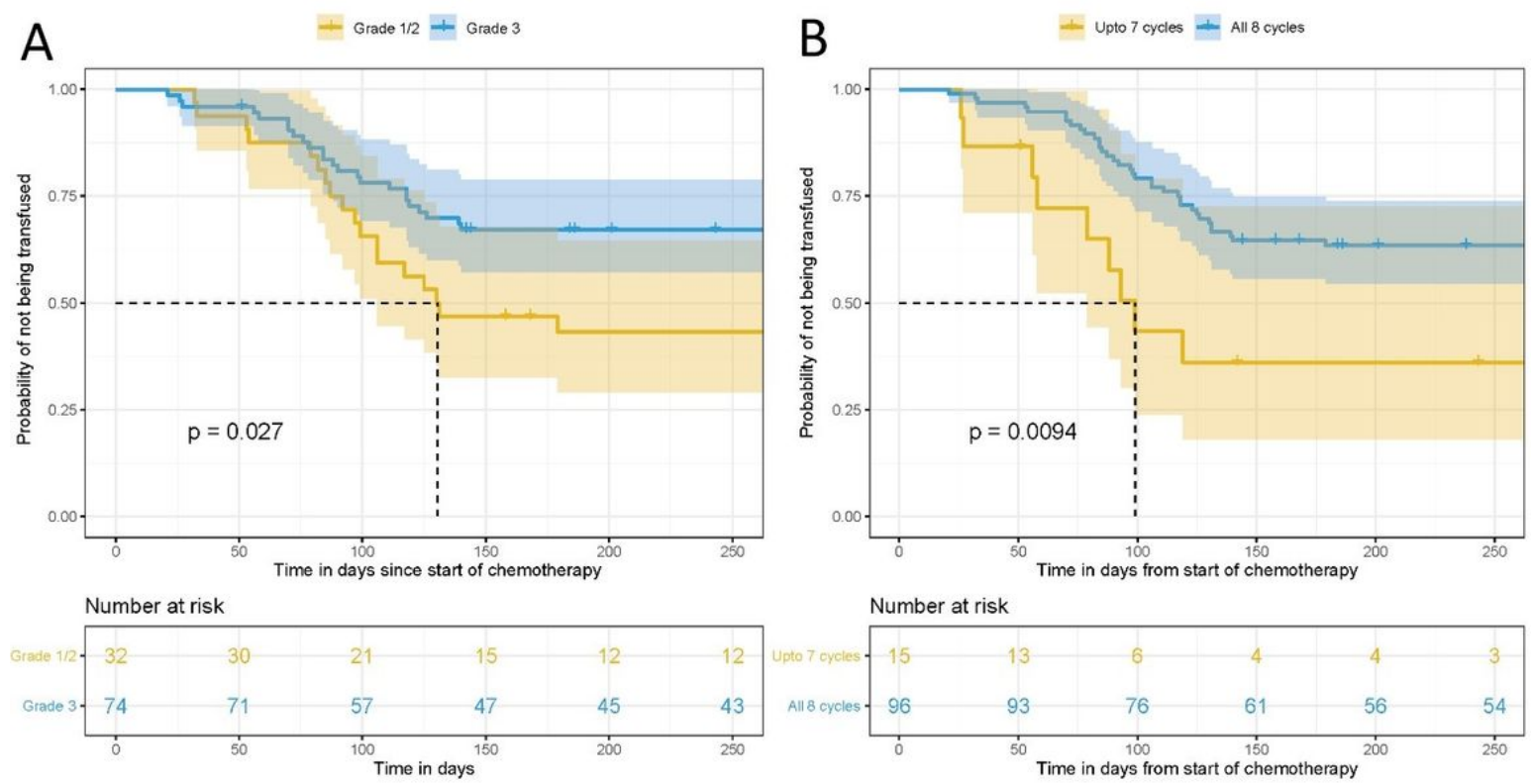

C

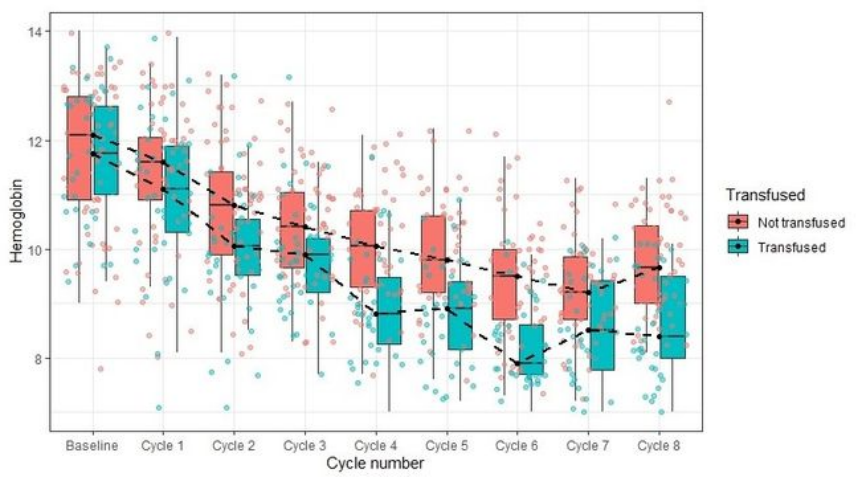

\section{Figure 1}

Time to event analysis of Grade of tumor (Graph A) and Number of cycles (Graph B) and day of transfusion from start of chemotherapy. (Graph C) Drop in hemoglobin with chemotherapy in Transfused group and Not-transfused group. 